\title{
Effectiveness of a Pulmonary Rehabilitation Program on Persistent Asthma Stratified for Severity
}

\author{
Elisabetta Zampogna, Mara Paneroni, Francesca Cherubino, Patrizia Pignatti, Monica Rudi, \\ Giulia Casu, Michele Vitacca, Antonio Spanevello, and Dina Visca
}

\begin{abstract}
BACKGROUND: Asthma is defined by airway inflammation associated with various respiratory symptoms, and pharmacologic treatment is based on inhaled corticosteroids and bronchodilators. Physical activity, educational training, nutritional support, and psychological counseling are considered part of non-pharmacologic treatment; however, studies so far have investigated the effect of single non-pharmacologic treatment. There are few studies that demonstrate the effect of comprehensive pulmonary rehabilitation, but no clear data are available regarding factors that can predict who could benefit the most. Our study aimed to assess the effect of a comprehensive 3-week pulmonary rehabilitation program on exercise tolerance and to identify baseline subject characteristics that may predict a better response to treatment. METHODS: This was a retrospective study. A team planned a pulmonary rehabilitation program: educational support; endurance training; and optional components, such as respiratory exercises and airway clearance techniques. The following data were collected before and after pulmonary rehabilitation: subject characteristics, smoking history, asthma severity, respiratory function and 6-min walk test (6MWT). RESULTS: We collected data on 515 subjects (202 males 39.2\%), age, mean \pm SD $63.9 \pm 10.4$ y), with $413(80.2 \%)$ having moderate-to-severe disease; and $455(88.4 \%)$ with stable respiratory symptoms $455(88.35 \%)$. At baseline, the percentage of predicted 6MWT in all subjects categorized by the Global Initiative for Asthma (GINA) steps was in the normal range, except for the subjects at step 5 , for which it was significantly lower $(P=.01)$. All subjects showed a significant improvement in exercise tolerance and oxygen saturation, together with a decrease in baseline dyspnea, muscle fatigue, and heart rate after pulmonary rehabilitation. Improvement of 6MWT was statistically significant, irrespective of the GINA categorization. The variables related to the improvement in 6MWT were age $(P<.001)$, smoking habit $(P=.034)$, and baseline 6MWT $(P<.001)$. CONCLUSIONS: Subjects with asthma at any GINA step seemed to benefit from a pulmonary rehabilitation program; analysis of our data highlighted that pulmonary rehabilitation was more beneficial in younger subjects with a smoking history and worse baseline exercise tolerance. Key words: pulmonary rehabilitation; exercise; asthma; 6MWT. [Respir Care 2019;64(12):1523-1530. @ 2019 Daedalus Enterprises]
\end{abstract}

\section{Introduction}

The primary goals of asthma treatment include complete symptom control, optimal management of limitations

Ms Zampogna, Dr Cherubino, Ms Rudi, Dr Spanevello, and Dr Visca are affiliated with Istituti Clinici Scientifici Maugeri IRCCS, Respiratory Rehabilitation of the Institute of Tradate (Varese), Tradate, Italy. Ms Paneroni and Dr Vitacca are affiliated with Istituti Clinici Scientifici Maugeri IRCCS, Respiratory Rehabilitation of the Institute of Lumezzane (Brescia), Lumezzane, Italy. Dr Pignatti is affiliated with Istituti Clinici Scientifici Maugeri IRCCS, Allergy and Immunology Unit of the Institute of Pavia, Pavia, Italy. Ms Casu, Dr Spanevello, and Dr Visca are in activities of daily living, and reduction of future exacerbation risk. ${ }^{1-4}$ Physical activity in patients with asthma is limited by the fear of experiencing symptoms during ex-

\footnotetext{
affiliated with the Department of Medicine and Surgery, Respiratory Diseases, University of Insubria, Varese-Como, Italy.

The authors have disclosed no conflicts of interest.

Correspondence: Elisabetta Zampogna MSc RRT, Istituti Clinici Scientifici Maugeri IRCCS, Via Salvatore Maugeri, 4, 27100 Pavia, Italy. E-mail: elisabetta.zampogna@icsmaugeri.it.
}

DOI: $10.4187 /$ respcare.06761 
ercise, ${ }^{5-10}$ whereas their reduced capacity to manage daily activities increases psychological distress, which affects health status and quality of life. ${ }^{6,11}$ However, regular physical activity has been shown to reduce the risk of asthma exacerbations. ${ }^{12}$

Supervised physical activity, as well as education programs, ${ }^{13}$ nutritional intervention, and psychological counseling, are considered part of non-pharmacologic asthma treatment. ${ }^{1,12}$ Results of a systematic review and metaanalysis indicate that exercise training may reduce airway hyperactivity and improve lung function and exercise capacity in subjects with asthma. ${ }^{14}$ It is worth noticing that, even if most of the studies performed so far highlight that exercise training is well tolerated and improves exertional symptoms, anxiety, depression, cardiovascular fitness, and health-related quality of life without affecting lung function; none of them have evaluated the influence of asthma severity and age on outcomes. . $^{5-12,15}$

Although pulmonary rehabilitation has been demonstrated to be effective, patients with asthma are not routinely referred for pulmonary rehabilitation, ${ }^{11}$ whereas there are few studies that demonstrate the effect of a comprehensive pulmonary rehabilitation program, ${ }^{11,14,16,17}$ with no clear data available regarding baseline factors that can predict who could most benefit from pulmonary rehabilitation, especially when stratified by disease severity. When considering the need to identify patients who can benefit more from pulmonary rehabilitation, our study aimed to assess the effect of a comprehensive 3-week pulmonary rehabilitation program on exercise tolerance in subjects with asthma as the primary outcome and to identify baseline patient characteristics that may help to predict a better response to pulmonary rehabilitation treatment.

\section{Methods}

\section{Study Design and Participants}

This retrospective study was conducted at Istituti Clinici Scientifici Maugeri of Tradate (Varese), Italy. We analyzed all the medical records of consecutive patients with asthma who followed a pulmonary rehabilitation program from January 2007 to June 2017. Data were collected through the hospital informatics system and completed with medical records. The ethic committee of Istituti Clinici Scientifici Maugeri approved the study protocol (2219, July 19, 2018). Inclusion criteria were the following: patients $\geq 18 \mathrm{y}$, a diagnosis of asthma according to current Global Initiative for Asthma (GINA) guidelines, ${ }^{1}$ pharmacologic treatment for asthma according to GINA guidelines over the previous 12 months, adherence of at least $80 \%$ to a standard rehabilitation program of 15 sessions, ${ }^{18}$ and the ability to perform and complete a 6-min walk test (6MWT). Exclusion criteria were the following: the pres-

\section{QUICK LOOK}

\section{Current knowledge}

Asthma is defined by airway inflammation associated with respiratory symptoms, including wheezing, shortness of breath, chest tightness, and cough. Supervised physical activity, as well as educational training, nutritional intervention, and psychological counseling, are considered part of non-pharmacologic asthma treatment. Exercise training is well tolerated by patients with asthma and improves exertional symptoms, cardiovascular fitness, and health-related quality of life without affecting lung function.

\section{What this paper contributes to our knowledge}

Subjects with asthma benefited from a pulmonary rehabilitation program regardless of disease severity in terms of respiratory symptoms, oxygenation at rest, and exercise performance. The subjects who benefitted more from pulmonary rehabilitation were younger and with a worse lung-function impairment, lower baseline 6-min walk distance, and a smoking history.

ence of concomitant diseases that could compromise the pulmonary rehabilitation trial and a diagnosis of COPD.

\section{Rehabilitative Intervention}

The multidisciplinary team involved in the pulmonary rehabilitation program included a pulmonologist (MV, AS, DV), a nurse, a respiratory therapist (EZ, MP, MR), a psychologist, and a dietitian. The 3-week rehabilitation trial included preand post-rehabilitation evaluations of lung function static and dynamic volumes according to the American Thoracic Society, ${ }^{19}$ performed by trained staff (EZ, MR, DV) in a lung function laboratory with body plethysmograph (Masterlab Body Jaeger, Würzburg, Germany), blood gas analysis (automatic analyzer ABL 820 Radiometer Medical, Brønshøj, Denmark), chest radiograph, 6MWT (according to guidelines), ${ }^{20}$ and respiratory symptoms. ${ }^{21}$

The pulmonary rehabilitation program was tailored for each subject's needs and included endurance training; educational support; and optional components, such as breathing strategies (breathing retraining or pursed-lips breathing in the case of dynamic hyperinflation or dyspnea, which limits exercise capacity) and airway clearance techniques (in the case of retained secretions). Moreover, according to individual needs, psychological support, relaxation techniques (when the psychological assessment found an emotional impact of the illness, ie, anxiety state or depressive symptom) $)^{12,22,23}$ and nutritional counseling (subjects who 


\section{Pulmonary Rehabilitation in Asthma}

Table 1. Pulmonary Rehabilitation Details

\begin{tabular}{|c|c|c|}
\hline Component & Detail & Session \\
\hline \multicolumn{3}{|l|}{ Pulmonary rehabilitation components } \\
\hline Endurance training (cycle ergometer) & $\begin{array}{l}30 \text { min ( } 5 \text { min warm-up, } 20 \text { min training and } 5 \text { min cool-down) at } \\
\text { constant load (starting from the } 50-70 \% \text { of theoretical watt } \\
\text { maximum, calculated with Luxon equation,* and adjusted on } \\
\text { subject's tolerance } \dagger\end{array}$ & $\begin{array}{l}15 \text { Sessions, one time a day, } \\
5 \mathrm{~d} / \mathrm{wk}\end{array}$ \\
\hline \multirow[t]{4}{*}{ Educational program } & Optimization of inhalation techniques & 2 Individual sessions \\
\hline & Peak expiratory flow monitoring & Individual daily session \\
\hline & Characteristics of asthma and the Asthma Action Plan & 2 Face-to-face sessions \\
\hline & Lifestyle, physical activity, and maintenance programs & 2 Group sessions \\
\hline \multicolumn{3}{|l|}{ Optional components } \\
\hline Respiratory exercises & $30 \mathrm{~min}$ & $1 \mathrm{Session} / \mathrm{d}$ \\
\hline Airways clearance techniques & $30 \min$ & 1/2 Session/d \\
\hline Psychological support relaxation technique & from 30 to 60 mins & 3 Sessions/wk \\
\hline Nutritional counseling & $\begin{array}{l}\text { Progressive muscles relaxation, Jacobson method, } 30 \mathrm{~min} \\
\text { from } 30 \text { to } 60 \mathrm{mins}\end{array}$ & $\begin{array}{l}5 \text { Sessions/wk } \\
2 \text { Sessions }\end{array}$ \\
\hline \multicolumn{3}{|c|}{$\begin{array}{l}\text { Each session and exercise was supervised by a respiratory therapist. } \\
* \text { From Reference } 34 . \\
\dagger \text { From Reference } 35 \text {. }\end{array}$} \\
\hline
\end{tabular}

were overweight or obese, or who had diabetes or other metabolic issues) were added to provide a personalized diet. Details of the pulmonary rehabilitation are shown in the Table 1.

\section{Outcome Measures}

The following data were collected in an electronic database: subject characteristics (age, sex); comorbidities; smoking history and pack-years; asthma severity according to GINA classification; respiratory function: FEV1 (L and \% of theoretical value) and FVC ( $\mathrm{L}$ and \% of theoretical value), $\mathrm{FEV}_{1} / \mathrm{FVC}$, residual volume percentage, $\mathrm{P}_{\mathrm{aO}_{2}}$ (in $\mathrm{mm} \mathrm{Hg}$ ), $\mathrm{P}_{\mathrm{aCO}_{2}}$ (in $\mathrm{mm} \mathrm{Hg}$ ), $\mathrm{pH}$, arterial oxygen saturation $\left(\mathrm{S}_{\mathrm{aO}_{2}}\right)$ before (T0) and after (T1) pulmonary rehabilitation program; and 6MWT: walk distance and percentage predicted, heart rate, $\mathrm{S}_{\mathrm{pO}_{2}}$ ) perceived dyspnea and muscular fatigue before and after the test, measured with the modified Borg scale at T0 and T1.

\section{Statistical Analysis}

All statistical analyses were conducted by using the dedicated software STATA 11.2 (StataCorp, College Station, Texas). The before to after difference in effort tolerance (6MWT) was evaluated by using the paired $t$ test. To predict factors related to effort tolerance improvement, a single linear regression analysis was performed. The difference in meters between the final and initial 6MWT was considered a dependent variable. All other anthropometric, clinical, and functional collected measures were considered as independent variables. With regard to the severity

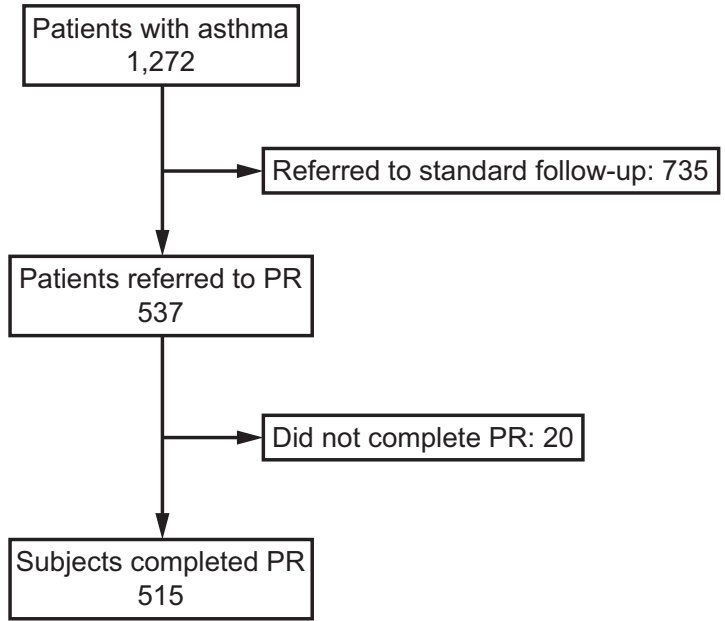

Fig. 1. Flow chart. $P R=$ pulmonary rehabilitation.

of the disease, we evaluated the different percentages of the 6MWT predicted value among the 5 GINA steps at baseline and after the rehabilitative treatment by using the one-way analysis of variance test. $P<.05$ was considered statistically significant.

\section{Results}

The flow chart of the study design is shown in Figure 1. We collected data of 515 subjects with asthma who completed the program. The study population included $313 \mathrm{fe}-$ males and 202 males. Baseline demographics, anthropometrics, and physiologic and clinical data of the subjects are shown in Table 2 . The cohort was mainly composed of 
Table 2. Clinical and Functional Characteristics of Included Subjects at Baseline

\begin{tabular}{|c|c|}
\hline Characteristic & Result \\
\hline \multicolumn{2}{|l|}{ Sex, $n(\%)$} \\
\hline Female & $313(60.78)$ \\
\hline Male & $202(39.22)$ \\
\hline \multicolumn{2}{|l|}{ Admission diagnosis, $n(\%)$} \\
\hline Stable asthma & $455(88.35)$ \\
\hline Exacerbation & $60(11.65)$ \\
\hline \multicolumn{2}{|l|}{ GINA steps, $n(\%)$} \\
\hline 1 & $12(2.33)$ \\
\hline 2 & $34(6.60)$ \\
\hline 3 & $56(10.87)$ \\
\hline 4 & $399(77.48)$ \\
\hline 5 & $14(2.72)$ \\
\hline \multicolumn{2}{|l|}{ Concomitant diseases, $n(\%)$} \\
\hline Cardiac & $31(6.01)$ \\
\hline Vascular & $22(4.27)$ \\
\hline Respiratory* & $382(74.17)$ \\
\hline Ophthalmologic and ORL & $20(3.88)$ \\
\hline Upper gastrointestinal & $35(6.79)$ \\
\hline Endocrine, metabolic & $217(42.13)$ \\
\hline Other & $29(5.61)$ \\
\hline \multicolumn{2}{|l|}{ Age } \\
\hline Entire cohort, mean \pm SD y & $63.93 \pm 10.37$ \\
\hline \multicolumn{2}{|l|}{ At GINA step, age (\%) y } \\
\hline 1 & $56.25(8.09)$ \\
\hline 2 & $65.11(8.35)$ \\
\hline 3 & $64.02(11.70)$ \\
\hline 4 & $64.23(10.33)$ \\
\hline 5 & $56.78(7.55)$ \\
\hline \multicolumn{2}{|l|}{$\mathrm{PFT}$, mean $\pm \mathrm{SD}$} \\
\hline $\mathrm{FEV}_{1}, \mathrm{~L}$ & $1.88 \pm 0.68$ \\
\hline $\mathrm{FEV}_{1}, \%$ & $82.17 \pm 22.48$ \\
\hline FVC, L & $2.82 \pm 2.71$ \\
\hline FVC, $\%$ & $96.70 \pm 52.90$ \\
\hline $\mathrm{FEV}_{1} / \mathrm{FVC}$ & $0.67 \pm 12$ \\
\hline $\mathrm{RV}, \%$ & $137.43 \pm 34.85$ \\
\hline \multicolumn{2}{|l|}{ Blood gas analysis } \\
\hline $\mathrm{P}_{\mathrm{aO}}, \mathrm{mm} \mathrm{Hg}$ & $77.62 \pm 8.75$ \\
\hline $\mathrm{P}_{\mathrm{aCO}_{2}}, \mathrm{~mm} \mathrm{Hg}$ & $36.93 \pm 3.68$ \\
\hline $\mathrm{pH}$ & $7.43 \pm 0.03$ \\
\hline $\mathrm{S}_{\mathrm{aO}_{2}}, \%$ & $95.56 \pm 1.48$ \\
\hline \multicolumn{2}{|l|}{$6 \mathrm{MWT}$, mean $\pm \mathrm{SD}$} \\
\hline Distance, $\mathrm{m}$ & $459.92 \pm 94.10$ \\
\hline Percentage & $98.41 \pm 19.23$ \\
\hline Resting heart rate, beats/min & $77.94 \pm 11.41$ \\
\hline Maximum heart rate, beats/min & $112.67 \pm 15.50$ \\
\hline Resting $\mathrm{S}_{\mathrm{pO}_{2}}, \%$ & $94.97 \pm 1.78$ \\
\hline Nadir $\mathrm{S}_{\mathrm{pO}_{2}}, \%$ & $92.27 \pm 2.77$ \\
\hline Resting Borg dyspnea, $n$ & $0.82 \pm 1.06$ \\
\hline Borg dyspnea post $6 \mathrm{MWT}, n$ & $3.28 \pm 1.94$ \\
\hline Resting Borg fatigue, $n$ & $0.67 \pm 1.16$ \\
\hline Borg fatigue post $6 \mathrm{MWT}, n$ & $2.97 \pm 2.20$ \\
\hline $\begin{array}{l}\text { * Bronchiectasis, upper respiratory tract dis } \\
\text { GINA = Global Initiative for Asthma } \\
\text { ORL }=\text { otorhinolaryngology } \\
\text { PFT = pulmonary function test } \\
\text { RV }=\text { residual volume } \\
\text { 6MWT }=6 \text {-min walk test }\end{array}$ & \\
\hline
\end{tabular}

women with asthma who were clinically stable and classified as GINA step 4. Among the study population, the most common comorbidities were obesity (30\%), bronchiectasis (15.3\%), type 2 diabetes (4\%), and upper respiratory tract diseases $(2.5 \%)$. Borg dyspnea and fatigue were missing for $7.9 \%$ of the entire cohort. The sex distribution in the different GINA steps is shown in Figure 2.

At baseline, the percentage of predicted 6MWT in all GINA steps was in the normal range, except for the subjects at step 5, for which it was significantly lower $(80.14 \% \pm 20.30 \%, P=.01)$ (Fig. 3). Overall, the subjects completed the 6MWT before and after the pulmonary rehabilitation program. The pre-to-post change in 6MWT is described in Table 3. All the subjects showed a significant improvement in exercise tolerance and oxygen saturation after pulmonary rehabilitation, together with a decrease in baseline dyspnea and heart rate. The 6-min walk distance increased by $39.62 \mathrm{~m}$ on average $(95 \% \mathrm{CI}$ -18 to $123 \mathrm{~m})$.

With regard to the severity of the disease, a box plot of percentages of the predicted value of 6MWT among the 5 GINA steps at baseline and the changes after the rehabilitative treatment are shown in Figure 2. Improvement of 6MWT was statistically significant, irrespective of the GINA groups. The variables, according to the univariate linear regression analysis (Table 4), significantly related to the improvement in 6MWT were the following: age $(P<.001)$, smoking habit $(P=.034)$, and baseline 6MWT $(P<.001)$. Younger subjects with a smoking habit and lower effort tolerance at the beginning of the rehabilitative intervention were the ones most likely to improve their functional capacity after the rehabilitation program.

\section{Discussion}

Our retrospective study aimed to assess the effect of a 3-week pulmonary rehabilitation program on exercise tolerance in subjects with asthma at any stage of disease and to identify baseline subject characteristics that may predict a better response to treatment. Analysis of our data showed a significant improvement in terms of exercise performance, dyspnea, muscle fatigue, and oxygenation at rest in the subjects with asthma, independent from disease severity, which suggested that patients with asthma may also benefit from a comprehensive pulmonary rehabilitation program (including endurance training, respiratory exercises, psychological support, and nutritional counseling). A higher improvement in exercise tolerance was related to a lower baseline 6-min walk distance, younger age, and the presence of a smoking habit. Furthermore, to the best of our knowledge, this was the first study with such a large cohort of subjects with asthma.

In our study, the average baseline 6MWD was $\sim 460 \mathrm{~m}$. It is known that age, height, weight, and sex independently 


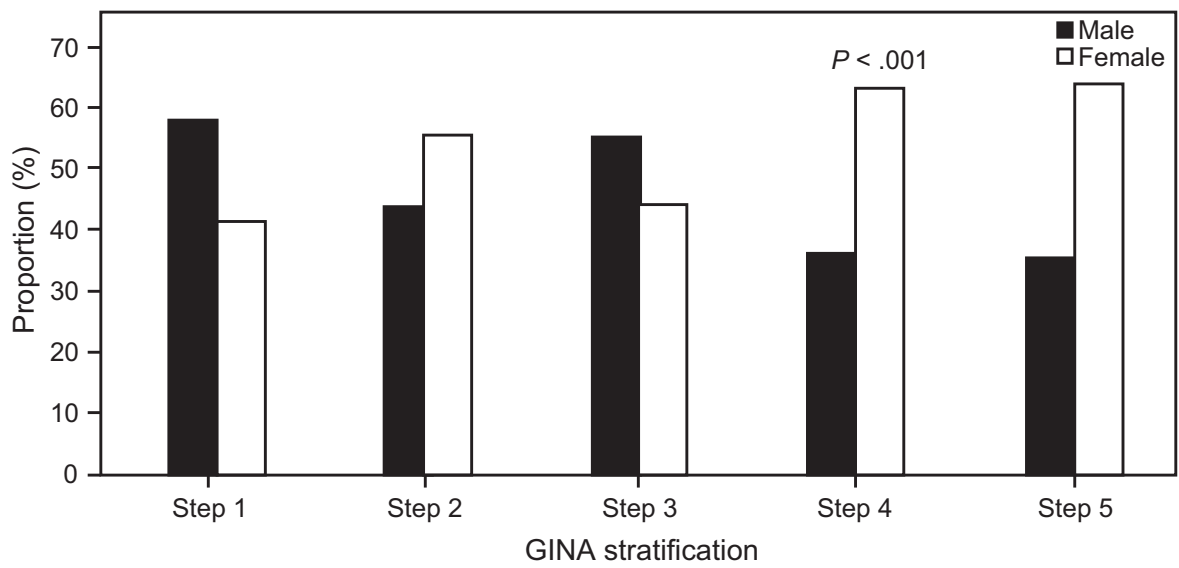

Fig. 2. Sex distribution.
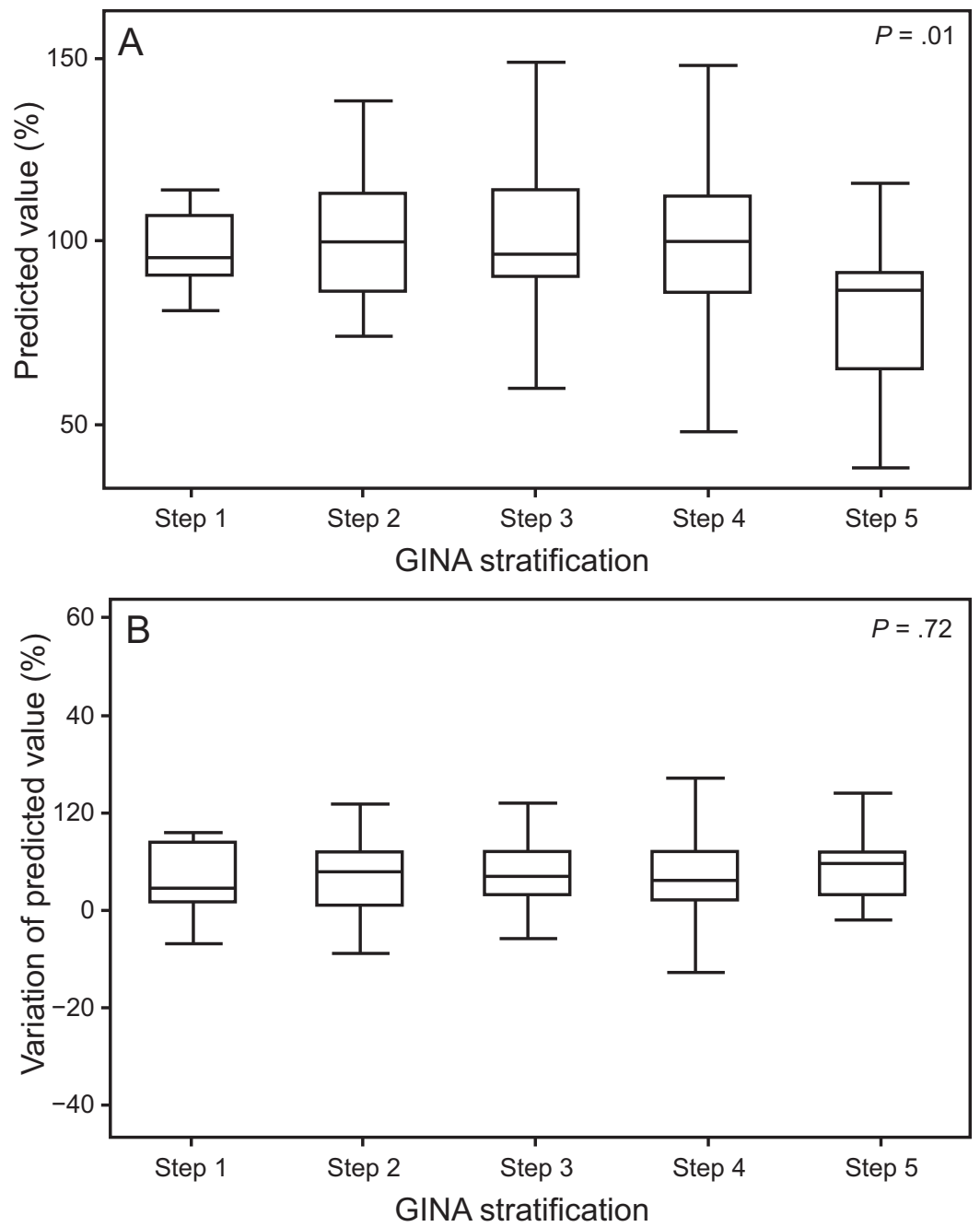

Fig. 3. Box plots of percentage of the 6-min walk test. A: Baseline. B: pre pulmonary rehabilitation-post pulmonary rehabilitation. Boxes denote variation from minimum to maximum, interquartile range, and median of data. 
Table 3. Entire Cohort Pre-to-Post Pulmonary Rehabilitation Program Change in 6MWT

\begin{tabular}{lccr}
\hline \hline \multicolumn{1}{c}{ Parameter } & T0 & T1 & $P$ \\
\hline 6MWD, $\mathrm{m}$ & $459.99 \pm 94.10$ & $499.61 \pm 89.99$ & $<.001$ \\
Resting Borg dyspnea, $n$ & $0.90 \pm 1.05$ & $0.57 \pm 0.82$ & $<.001$ \\
Resting Borg fatigue, $n$ & $0.67 \pm 1.16$ & $0.43 \pm 0.87$ & $<.001$ \\
Resting heart rate, beats/min & $77.94 \pm 11.41$ & $76.76 \pm 11.10$ & .01 \\
Mean resting $\mathrm{S}_{\mathrm{pO}_{2}}, \%$ & $94.97 \pm 1.78$ & $95.46 \pm 1.64$ & $2.63 \pm 1.75$ \\
Borg dyspnea post 6MWT, $n$ & $3.28 \pm 1.94$ & $2.48 \pm 1.97$ & \\
Borg fatigue post 6MWT, $n$ & $2.97 \pm 2.20$ & & \\
& & & \\
Data are mean \pm SD. & & & \\
6MWD $=$ 6-min walk distance & & & \\
T0 $=$ before the pulmonary rehabilitation program & & & \\
$\mathrm{T} 1=$ after the pulmonary rehabilitation program & & & \\
\hline
\end{tabular}

Table 4. Univariate Linear Regression Analysis

\begin{tabular}{llllrr}
\hline \hline Dependent Variable & \multicolumn{1}{c}{$\begin{array}{c}\text { Independent } \\
\text { Variable }\end{array}$} & B & 95\% CI & Standard Error & $\mathrm{R}^{2}$ \\
\hline Pre-to-post change & Baseline 6MWD, m & -0.0160 & -0.200 to 0.120 & -0.020 & 0.11 \\
6MWD, m & Age, y & -0.747 & -1.123 to 0.370 & 0.191 & 0.02 \\
& Smoking habit & 4.659 & $0.357-8.96$ & 2.190 & 0.01
\end{tabular}

$\overline{6 \mathrm{MWD}=6 \text {-min walk }}$ distance

affect the 6MWT. The performance of our cohort was below expected for a healthy population, even if the percentage of predicted results were within normal limits. ${ }^{24,25}$ These data might reflect the fact that patients with asthma reduce their physical activity and exercise capacity because of the fear of experiencing symptoms during or after exercise. ${ }^{5-7}$ Furthermore, we could not exclude the possibility that 6MWT could be affected by body weight in $30 \%$ of the total study population, as documented in previous studies. ${ }^{26}$ In this study, an improvement in terms of functional performance, dyspnea, and muscle fatigue was obtained in all the subjects, independent from asthma severity.

Our results were in line with other previous studies $^{11,16,17}$ with fewer subjects. Many investigators reported that exercise training is well tolerated by patients with asthma and is able to improve symptoms, cardiovascular fitness, health-related quality of life, anxiety, depression, pulmonary function, and the 6MWT, and to reduce bronchial hyperresponsiveness and serum proinflammatory cytokines. . $^{5,11,16,17,27,28}$

Our subjects were mainly middle-age women with more severe asthma, as previously reported. ${ }^{29}$ Interestingly, a higher $\mathrm{CI}$ in effort tolerance was found in more severe GINA groups (eg, GINA step 4); this might reflect the increase in variability of functional impairment of patients when severity of the disease increases. In this group, there are probably subjects with a normal functional ability but also subjects with walking disability due to dyspnea or fatigue, whereas the majority of subjects with less severe asthma had a functional ability close to normality. Again, analysis of our data showed a significant reduction of functional capacity in the subjects at GINA step 5, and a 6MWT $<82 \%$ of predicted, which is usually considered a threshold of normality. ${ }^{26}$ In our study, the baseline walk distance increased by $40 \mathrm{~m}$ after pulmonary rehabilitation. This result was similar to those reported in another study that investigated subjects with asthma with different levels of disease control. ${ }^{16}$ Better results are reported in the study of Lingner et al, ${ }^{11}$ in which the walk distance increased by $60 \mathrm{~m}$. When compared with our study, the different level of improvement may be due to different subject characteristics; our subjects were older, with more severe obstruction.

Our study showed an improvement in the resting Borg dyspnea scale, resting heart rate, and resting oxygen saturation as demonstration of significant improvement in post-exercise dyspnea and muscle fatigue, although an important increase in effort tolerance. This result support the positive role of pulmonary rehabilitation in patients with asthma. Interestingly, the strongest variable to explain the improvement in exercise was the baseline 6MWD. Age and smoking habit, although significant, presented a lower $\mathrm{R}^{2}$, with less affect on the outcome. These results confirmed that the rehabilitation 


\section{Pulmonary Rehabilitation in Asthma}

benefits were often more pronounced in patients who were more disabled.

According to Demoly et al, ${ }^{30}>50 \%$ of subjects with asthma in 5 European countries, including Italy, reported poor symptom control, thus additional studies are required to better understand how to improve the role of non-pharmacologic treatment, such as patient education and training. As part of the pulmonary rehabilitation program, pulmonologists (MV, AS, DV) taught our subjects about disease management and asthma action plans to improve respiratory symptom control, according to our previous experience, which we named "asthma school." 31 We do not know how this educational program has influenced, per se, the positive results. However, previous studies showed that combining effective management of inhaled medications and pulmonary rehabilitation elicit better results than either therapy or pulmonary rehabilitation alone. ${ }^{32,33}$

Our study had some limitations. As with all retrospective studies, these were missing data $(7.9 \%$ of the Borg values, asthma control, drug history, quality of life and subjective customer satisfaction), which led to a risk of decreasing accuracy and a lack of important information. Another limitation was that we were not able to extrapolate the single or synergic role of medication readjustments and the rehabilitation program in our multidisciplinary program. However our data mirror real-life conditions encountered by health-care services in selecting patients who may benefit from pulmonary rehabilitation.

\section{Conclusions}

Our results showed that subjects with asthma at any GINA step may benefit from a comprehensive pulmonary rehabilitation program in terms of respiratory symptoms, muscle fatigue, and oxygenation at rest and during exercise. In addition, our data highlighted that the pulmonary rehabilitation program was more beneficial in younger subjects with smoking history and worse baseline effort tolerance. However, additional prospective studies are needed to better define the characteristics of patients who may benefit the most and to evaluate the effective role of each component of a comprehensive pulmonary rehabilitation to reach better disease control.

\section{REFERENCES}

1. Global Initiative for Asthma: Global Strategy for Asthma Management and Prevention. 2018. Available at: http://ginasthma.org/wpcontent/uploads/2018/04/wms-GINA-2018-report-V1.3-002.pdf. Accessed on December 10, 2018.

2. Lazarinis N, Jørgensen L, Ekström T, Bjermer L, Dahlén B, Pullerits $\mathrm{T}$, et al. Combination of budesonide/formoterol on demand improves asthma control by reducing exercise-induced bronchoconstriction. Thorax 2014;69(2):130-136.
3. Nathan RA, Dorinsky P, Rosenzweig JR, Shah T, Edin H, Prillaman B. Improved ability to perform strenuous activities after treatment with fluticasone propionate/salmeterol combination in patients with persistent asthma. J Asthma 2003;40(7):815-822.

4. Vermeulen F, Garcia G, Ninane V, Laveneziana P. Activity limitation and exertional dyspnea in adult asthmatic patients: What do we know? Respir Med 2016;117:122-130.

5. Carson KV, Chandratilleke MG, Picot J, Brinn MP, Esterman AJ, Smith BJ. Physical training for asthma. Cochrane Database of Syst Rev 2013;30(9):CD001116.

6. Turner S, Eastwood P, Cook A, Jenkins S. Improvements in symptoms and quality of life following exercise training in older adults with moderate/severe persistent asthma. Respiration 2011;81(4):302310 .

7. Mendes FA, Gonçalves RC, Nunes MP, Saraiva-Romanholo BM, Cukier A, Stelmach R, et al. Effects of aerobic training on psychosocial morbidity and symptoms in patients with asthma: a randomized clinical trial. Chest 2010;138(2):331-337.

8. Ramos E, de Oliveira LV, Silva AB, Costa IP, Corrêa JC, Costa D, et al. Peripheral muscle strength and functional capacity in patients with moderate to severe asthma. Multidiscip Respir Med 2015; 10(1):3.

9. Carlton BG, Lucas DO, Ellis EF, Conboy-Ellis K, Shoheiber O, Stempel DA. The status of asthma control and asthma prescribing practices in the United States: results of a large prospective asthma control survey of primary care practices. J Asthma 2005;42(7):529535 .

10. Mancuso CA, Sayles W, Robbins L, Phillips EG, Ravenell K, Duffy $\mathrm{C}$, et al. Barriers and facilitators to healthy physical activity in asthma patients. J Asthma 2006;43(2):137-143.

11. Lingner H, Ernst S, Großhennig A, Djahangiri N, Scheub D, Wittmann M, Schultz K. Asthma control and health-related quality of life one year after inpatient pulmonary rehabilitation: the ProKAR Study. J Asthma 2015;52(6):614-621.

12. Sommaruga M, Spanevello A, Migliori GB, Neri M, Callegari S, Majani G. The effects of a cognitive behavioral intervention in asthmatic patients. Monaldi Arch Chest Dis 1995;50(5):398-402.

13. Spruit MA, Singh SJ, Garvey C, ZuWallack R, Nici L, Rochester C, et al.; ATS/ERS Task Force on Pulmonary Rehabilitation. An official American Thoracic Society/European Respiratory Society statement: key concepts and advances in pulmonary rehabilitation. Am J Respir Crit Care Med 2013;188(8):e13-e64.

14. Eichenberger PA, Diener SN, Kofmehl R, Spengler CM. Effects of exercise training on airway hyperreactivity in asthma: a systematic review and meta-analysis. Sports Med 2013;43(11):1157-1170.

15. Weatherald J, Lougheed MD, Taillé C, Garcia G. Mechanisms, measurement and management of exertional dyspnea in asthma: number 5 in the series "exertional dyspnoea" edited by Pierantonio Lavenezlana and Piergiuseppe Agostoni. Eur Respir Rev 2017;14:26(144). pii: 170015.

16. Sahin H, Naz I. Comparing the effect of pulmonary rehabilitation in patients with uncontrolled and partially controlled asthma. J Asthma 2019;56(1):87-94.

17. França-Pinto A, Mendes FA, de Carvalho-Pinto RM, Agondi RC, Cukier A, Stelmach R, et al. Aerobic training decreases bronchial hyperresponsiveness and systemic inflammation in patients with moderate or severe asthma: a randomized controlled trial. Thorax 2015; 70(8):732-739.

18. Ries AL, Bauldoff GS, Carlin BW, Casaburi R, Emery CF, Mahler DA, et al. Pulmonary rehabilitation: joint ACCP/AACVPR evidence-based clinical practice guidelines. Chest 2007;131(5 Suppl): $4 \mathrm{~S}-42 \mathrm{~S}$. 


\section{Pulmonary Rehabilitation in Asthma}

19. Celli BR, MacNee W; ATS/ERS Task Force. Standards for the diagnosis and treatment of patients with COPD: a summary of the ATS/ERS position paper. Eur Respir J 2004;23(6):932-946.

20. ATS Committee on Proficiency Standards for Clinical Pulmonary Function Laboratories. ATS statement: guidelines for the six-minute walk test. Am J Respir Crit Care Med 2002;166(1):111-117.

21. Borg E, Borg G, Larsson K, Letzter M, Sundblad BM. An index for breathlessness and leg fatigue. Scand J Med Sci Sports 2010;20(4): 644-650.

22. Kew KM, Nashed M, Dulay V, Yorke J. Cognitive behavioral therapy (CBT) for adults and adolescents with asthma. Cochrane Database Syst Rev 2016;9:CD011818.

23. Nickel C, Kettler C, Muehlbacher M, Lahmann C, Tritt K, Fartacek $\mathrm{R}$, et al. Effect of progressive muscle relaxation in adolescent female bronchial asthma patients: a randomized, double-blind, controlled study. J Psychosom Res 2005;59(6):393-398.

24. Gibbons WJ, Fruchter N, Sloan S, Levy RD. Reference values for a multiple repetition 6-minute walk test in healthy adults older than 20 years. J Cardiopulm Rehabil 2001;21(2):87-93.

25. Enright PL, Sherrll DL. Reference equations for the six-minute walk in healthy adults. Am J Respir Crit Care Med 1998;158(5 Pt 1): 1384-1387.

26. Troosters T, Gosselink R, Decramer M. Six minute walking distance in healthy elderly subjects. Eur Resp J 1999;14(2):270-274.

27. Ritz T, Rosenfield D, Steptoe A. Physical activity, lung function, and shortness of breath in the daily life of individuals with asthma. Chest 2010;138(4):913-918.
28. Trevor JL, Bhatt SP, Wells JM, Kirkpatrick d, Schumann C, Hitchcock J, Dransfield MT. Benefits of completing pulmonary rehabilitation in patients with asthma. J Asthma 2015;52(9):969-973.

29. Zein JG, Erzurum SC. Asthma is different in women. Curr Allergy Asthma Rep 2015;15(6):28

30. Demoly P, Gueron B, Annunziata K, Adamek L, Walters RD. Update on asthma control in five European countries: results of a 2008 survey. Eur Respir Rev 2010;19(116):150-157.

31. Neri M, Migliori GB, Spanevello A, Berra D, Nicolin E, Landoni $\mathrm{CV}$, et al. Economic analysis of two structured treatment and teaching programs on asthma. Allergy 1996;51(5):313-319.

32. Casaburi R, Kukafka D, Cooper CB, Witek TJ Jr, Kesten S. Improvement in exercise tolerance with the combination of tiotropium and pulmonary rehabilitation in patients with COPD. Chest 2005; 127(3):809-817.

33. Ambrosino N, Foglio K, Balzano G, Paggiaro PL, Lessi P, Kesten S. Tiotropium and exercise training in COPD patients: effects on dyspnea and exercise tolerance. Int J Chron Obstruct Pulmon Dis 2008; 3(4):771-780.

34. Luxton N, Alison JA, Wu J, Mackey MG. Relationship between field walking tests and incremental cycle ergometry in COPD. Respirology 2008;13(6):856-862.

35. Maltais F, LeBlanc P, Jobin J, Bérubé C, Bruneau J, Carrier L, et al. Intensity of training and physiologic adaptation in patients with chronic obstructive pulmonary disease. Am J Respir Crit Care Med 1997;155(2):555-561. 